\title{
Effect of Cold Deformation on the Friction-Wear Property of a Biomedical Nickel-Free High-Nitrogen Stainless Steel
}

\author{
Hao-Chuan Zhao ${ }^{1,2} \cdot$ Yi-Bin Ren $^{2} \cdot$ Jia-Hui Dong ${ }^{2} \cdot$ Xin-Min Fan ${ }^{1} \cdot$ Ke Yang ${ }^{2}$
}

Received: 1 September 2015/Revised: 7 December 2015/Published online: 26 February 2016

(C) The Chinese Society for Metals and Springer-Verlag Berlin Heidelberg 2016

\begin{abstract}
The microstructural, mechanical and corrosion properties of different cold-rolled biomedical nickel-free highnitrogen stainless steels (NFHNSSs) were investigated to study the effect of cold deformation on its dry wear resistance as well as corrosion-wear behaviors in distilled water and Hank's solution. The results indicated that NFHNSS was characterized by stable austenite and possessed excellent work-hardening capacity; due to increasing cold deformation, the corrosion resistance just decreased very slightly and the dry wear rate decreased initially but subsequently increased, while the corrosion-wear resistance was improved monotonically in both distilled water and Hank's solution in spite of the presence of corrosive ions. The friction coefficients for different cold-rolled NFHNSSs were very close under the same lubricating condition, but they were the largest in distilled water compared to that in dry wear tests and Hank's solution.
\end{abstract}

\section{KEY WORDS: Nickel-free high-nitrogen stainless steel; Cold deformation; Friction; Wear;} Lubricating condition

\section{Introduction}

Metallic materials such as pure titanium and titanium alloys, cobalt-based alloys, 316L or 317L stainless steels have been selected as medical implant materials because of their excellent mechanical properties compared to polymeric and ceramic materials [1-3]. When a metallic material is chosen to manufacture all kinds of implant devices or other components which are often in contact with human skin, it must possess proper mechanical properties, superior corrosion resistance and non-ferromagnetic behavior [4].

Available online at http://link.springer.com/journal/40195

Yi-Bin Ren

ybren@imr.ac.cn

1 Department of Materials Science and Engineering, Nanjing University of Science and Technology, Nanjing 210094 , China

2 Institute of Metal Research, Chinese Academy of Sciences, Shenyang 110016, China
Nowadays, stainless steels such as 316L and/or 317L have been extensively used due to their good combination of above-mentioned properties in addition to their relative inexpensiveness. Unfortunately, it has been reported that when orthopedic implants made of type 316L and/or 317L stainless steels are implanted in living bodies, they corrode and release chromium and nickel ions, especially nickel ions which prove to be toxic species and powerful allergens that are harmful to human health [5-7]. Therefore, a great many of attempts have been made to develop new types of stainless steels with little or no nickel.

The high-nitrogen nickel-free austenitic stainless steel (HNNFSS), developed to solve the problems brought by nickel, is a new type austenitic steel, which could be a substitute for type 316L and/or 317L stainless steels. Many studies showed that HNNFSS possesses excellent mechanical properties such as high yield strength, good ductility and fatigue resistance [8-10], outstanding corrosion resistance, i.e., pitting, crevice and stress corrosion $[11,12]$, and superior biocompatibility [13]. However, as it can be imagined, it is unavoidable for two contacting 
components to wear under a certain load or cyclic load, which may cause material's final failure, particularly when they are subjected to a corrosive environment like human body liquid. Thus, the wear resistance is equally important for biomaterials whether in vivo or in vitro.

Nitrogen has a beneficial effect on the friction-wear property of steels. After AISI 304L stainless steel was high-temperature gas nitrided, its nitrogen content increased and cavitation erosion resistance was improved up to 8.5 times [14]. Basak et al. [15] studied the adhesive wear resistance of an as-cast nitrogen-containing stainless steel and found that its wear resistance increased significantly after a part of nickel was replaced by nitrogen and manganese. The study by André Paulo Tschiptschin et al. [16] showed an increase in wear resistance with increasing nitrogen content. As for annealed HNNFSS, it also exhibits better wear resistance in comparison with type 316L/304 stainless steel [4, 17, 18]. Zhou et al. [17] compared the corrosion erosion wear resistance of $13 \mathrm{Cr} 24 \mathrm{Mn} 0.44 \mathrm{~N}$ and 316L stainless steels and the results showed that both the mass-loss ratio and synergism ratio of $13 \mathrm{Cr} 24 \mathrm{Mn} 0.44 \mathrm{~N}$ were smaller than those of $316 \mathrm{~L}$ whether in saline-sand slurry or in water-sand slurry. However, although coldworked implant devices are usually used in clinic, there are few studies on wear resistance of cold-deformed HNNFSS under different lubricating conditions according to the previously reported literatures.

In the present study, a new nickel-free austenitic stainless steel containing nitrogen content of $0.90 \%$ in weight was developed and cold-rolled to different reductions in thickness to investigate the effect of cold deformation on the dry wear resistance, corrosion-wear behaviors in the distilled water and Hank's solution.

\section{Materials and Methods}

\subsection{Materials}

The new type nickel-free high-nitrogen stainless steel developed by Institute of Metal Research, Chinese Academy of Science, and referred to as NFHNSS in this study was melted in a $50 \mathrm{~kg}$ pressurized induction furnace, followed by forging and hot rolled into steel plate with a thickness of $5 \mathrm{~mm}$. Chemical compositions of the NFHNSS are given in Table 1 . The steel plate was firstly annealed at $1150{ }^{\circ} \mathrm{C}$ for $1 \mathrm{~h}$, water-quenched and then

Table 1 Chemical compositions of NFHNSS (wt \%)

\begin{tabular}{lllllllll}
\hline $\mathrm{C}$ & $\mathrm{N}$ & $\mathrm{Cr}$ & $\mathrm{Mn}$ & $\mathrm{Mo}$ & $\mathrm{Si}$ & $\mathrm{S}$ & $\mathrm{P}$ & $\mathrm{Fe}$ \\
\hline 0.014 & 0.90 & 18.30 & 15.30 & 2.40 & 0.31 & 0.009 & 0.010 & Bal. \\
\hline
\end{tabular}

cold-rolled at room temperature to obtain $20,40,60 \%$ reductions in thickness values.

\subsection{Microstructural Observation and Mechanical Testing}

Specimens with the dimension of $10 \mathrm{~mm} \times 10 \mathrm{~mm}$ used for microstructural observations were cut from those coldrolled plates with different cold deformation (including the annealed steel), pre-milled successively with emery papers from No. 240 to No. 2000 grades, mirror-polished using alumina of $0.3 \mu \mathrm{m}$ and then electrochemical etched in $10 \%$ oxalic acid aqueous solution at $20 \mathrm{~V}$ for $15 \mathrm{~s}$. The microstructure evolution of NFHNSS after cold deformation was also examined using transmission electron microscopy (TEM) (Philips TECNAIG ${ }^{20}$, Holland) operated at $200 \mathrm{kV}$. To confirm the existing phases in different cold-rolled specimens, the XRD was carried out using a Rigaku D/max-RB diffractometer.

Dog bone-shaped flat tensile test specimens were prepared from those different cold-rolled and annealed plates with $27 \mathrm{~mm}$ parallel length, $7.5 \mathrm{~mm}$ gauge width and $25 \mathrm{~mm}$ original gauge length. The surface of gauge section of each specimen was treated using No. 2000 emery papers, washed with distilled water and finally cleaned in acetone and alcohol successively. Tensile tests of all specimens were conducted using a CMT 4304 type microcomputer-controlled electronic universal testing machine at a rate of $2 \mathrm{~mm} / \mathrm{min}$ at room temperature. Moreover, the micro-hardness values of polished specimens with different cold deformation were measured using a Vickers hardness tester (Micromet 5103, Buehler) under a load of $0.1 \mathrm{~kg}$.

\subsection{Electrochemical Experiments}

The specimens with different cold deformation were embedded in araldite and polished with 2000 grit emery papers to expose an area of $1 \mathrm{~cm}^{2}$ to act as working electrodes in the electrochemical experiments. Cyclic polarization tests were carried out using a computerized Gamry Reference 600 Potentiostat/Galvanostat/ZRA electrochemical system which was connected to a three-electrode cell composed of a saturated calomel electrode (SCE) acting as the reference electrode and a platinum plate used as the counter electrode. The Hank's solution was chosen as the electrolyte and its compositions are listed in Table 2. All cyclic polarization tests were conducted starting from $-0.2 \mathrm{~V}$ toward the anodic direction, ending when the current density reached $0.1 \mathrm{~mA} / \mathrm{cm}^{2}$ and then scanning reversely at a scan rate of $0.2 \mathrm{mV} / \mathrm{s}$. The initial potential was relative to open-circuit potential (OCP). It is worth 
Table 2 Compositions of the Hank's solution used in cyclic polarization and wear tests $(\mathrm{g} / \mathrm{L})$

\begin{tabular}{llllllll}
\hline $\mathrm{NaCl}$ & $\mathrm{KCl}$ & $\mathrm{Na}_{2} \mathrm{HPO}_{4}$ & $\mathrm{KH}_{2} \mathrm{PO}_{4}$ & $\mathrm{CaCl}_{2}$ & $\mathrm{MgSO}_{4} \cdot 7 \mathrm{H}_{2} \mathrm{O}$ & $\mathrm{Glucose}$ & $\mathrm{NaHCO}_{3}$ \\
\hline 8 & 0.4 & 0.12 & 0.06 & 0.14 & 0.41 & 0.9 & 0.35 \\
\hline
\end{tabular}

noting that the temperature of Hank's solution was kept at $(37 \pm 0.5){ }^{\circ} \mathrm{C}$ during each experiment.

\subsection{Wear Tests}

The $22 \mathrm{~mm} \times 24 \mathrm{~mm}$ specimens with different thickness for sliding wear tests were cut from those cold-rolled and annealed plates by using electrical discharge method, followed by abrading on abrasive papers from No. 240 to No. 2000 and mechanical polishing to get mirror-like surfaces. Before and after each test, the specimen was cleaned in distilled water, acetone and alcohol successively, after which its weight was measured using an electronic analytical balance with sensitivity of $0.1 \mathrm{mg}$ to get the wear weight loss. Pin-on-disk sliding wear tests were carried out in reciprocating motion mode using a tribometer frictionwear testing machine, and silicon nitride $\left(\mathrm{Si}_{3} \mathrm{~N}_{4}\right)$ balls with the diameter of $6 \mathrm{~mm}$ were fixed on a pin to serve as the friction counterpart. For each kind of cold-rolled specimen, all wear tests were conducted at a normal load of $10 \mathrm{~N}$ under three conditions which were dry wear at room temperature and corrosion-wear in distilled water as well as Hank's solution at the temperature of $(37 \pm 0.5){ }^{\circ} \mathrm{C}$ and other test parameters for all tests are listed in Table 3. Every sliding wear test under each condition was repeated at least three times and the average of those weight losses obtained in repeated tests was calculated to obtain the final sliding wear weight loss. The wear resistance was characterized by weight loss per unit sliding distance $(\Delta W)$, which was calculated from the following equation:

$W=\Delta W / L$

where $\Delta W$ is the weight loss and $L$ stands for the sliding distance.

After sliding wear tests, worn surfaces were observed using a Cambridge S360 scanning electron microscopy (SEM) and their micro-hardness were measured at a load of $0.1 \mathrm{~kg}$. In addition, elements on the worn surfaces of the specimens tested in Hank's solution were determined using
X-ray photoelectron spectroscopy (ESCALAB250, Thermo $\mathrm{VG})$ with $\mathrm{Al} K_{\alpha}$ radiation acting as the exciting source and the binding energy of adventitious carbon (C1 s: $284.6 \mathrm{eV})$ was taken as the reference.

\section{Results}

\subsection{Microstructures and Mechanical Properties}

Microstructures of NFHNSS specimens with different reductions in thickness are shown in Fig. 1, from which it can be seen that there were austenitic grains and many twins in the annealed specimen. After cold rolling, those equiaxial grains were deformed and the number of deformed grains and deformation bands grew larger with increasing reduction in thickness. The TEM results revealed many deformation bands together with few deformation twins in the $20 \%$ cold-rolled NFHNSS while extensive deformation twins could be observed in the $40 \%$ cold-rolled NFHNSS. In general, existence of martensite induced by strain in metastable austenitic stainless steels is easy after cold deformation [19, 20]. To confirm whether NFHNSS is stable or not, XRD of all cold-rolled specimens were carried out and the results are shown in Fig. 2; it reveals only single-phase austenite in all specimens and neither strain-induced martensite nor any other secondary phase was even introduced in the specimen with the maximum cold reduction in thickness. Nevertheless, due to grain refinement, micro-stress together with crystal deflection caused by cold rolling, the height of diffraction peaks corresponding (200), (311) and (222) crystal faces decreased gradually and that corresponding (220) crystal face became higher; full widths at half maximum intensity for all crystal faces mentioned above broadened gradually.

The variations in mechanical properties of NFHNSS with respect to cold reduction in thickness are shown in Fig. 3, from which one can see that the yield strength, tensile strength and hardness increased significantly while

Table 3 Parameters of sliding wear tests

\begin{tabular}{llllll}
\hline Parameter & $\begin{array}{l}\text { Sliding } \\
\text { distance }(\mathrm{m})\end{array}$ & $\begin{array}{l}\text { Maximum linear } \\
\text { speed }(\mathrm{cm} / \mathrm{s})\end{array}$ & $\begin{array}{l}1 / 2 \text { amplitude } \\
(\mathrm{mm})\end{array}$ & $\begin{array}{l}\text { Frequency } \\
(\mathrm{Hz})\end{array}$ & $\begin{array}{l}\text { Time for one } \\
\text { experiment }(\mathrm{min})\end{array}$ \\
\hline Value & 1000 & 15 & 9 & 2.65 & 174 \\
\hline
\end{tabular}



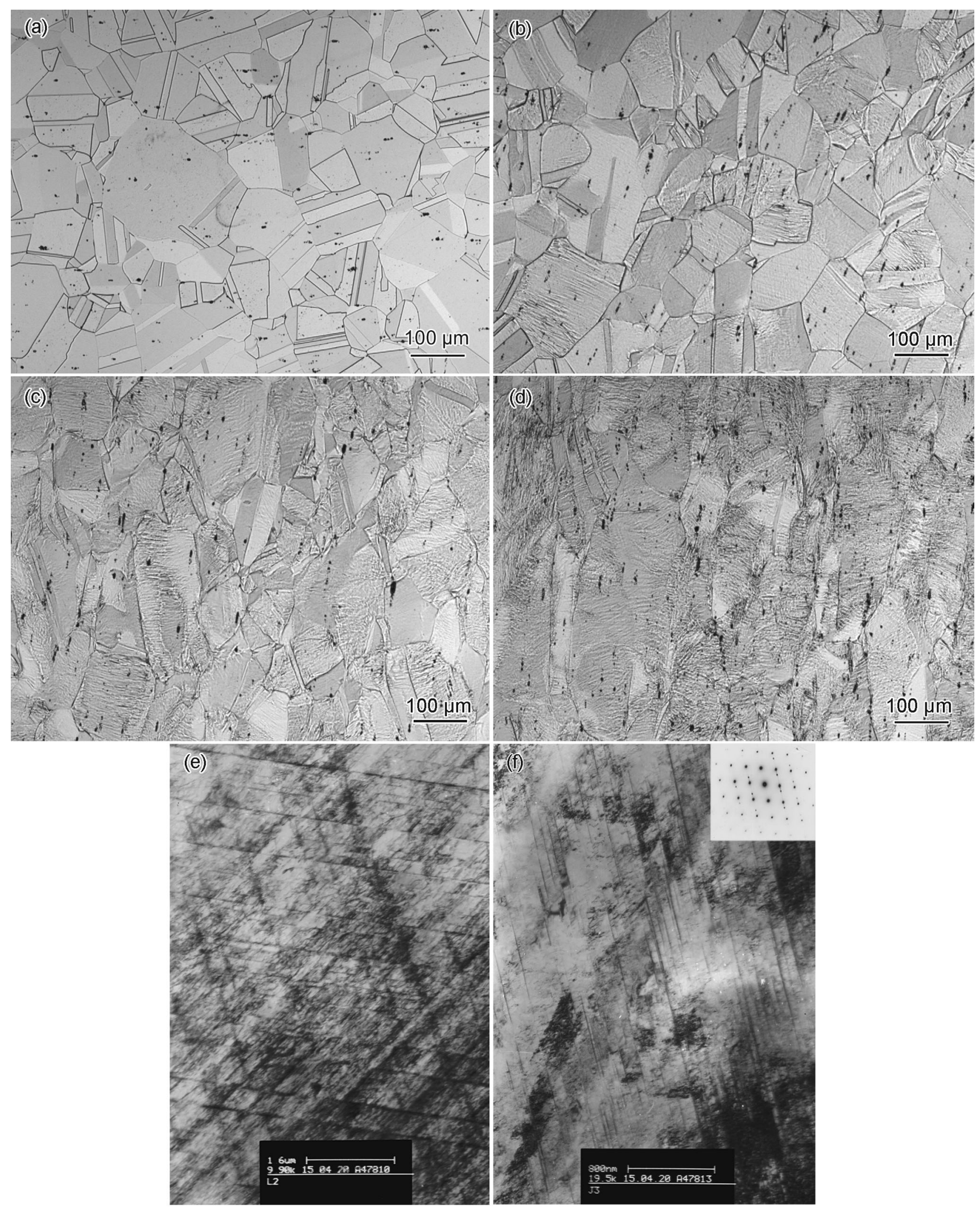

Fig. 1 Optical micrographs of NFHNSS specimens with the cold reduction of $0 \mathbf{a}, 20 \% \mathbf{b}, 40 \% \mathbf{c}$ and $60 \% \mathbf{d}$ in thickness and TEM images of $20 \%$ e and $40 \%$ f cold-rolled NFHNSS 


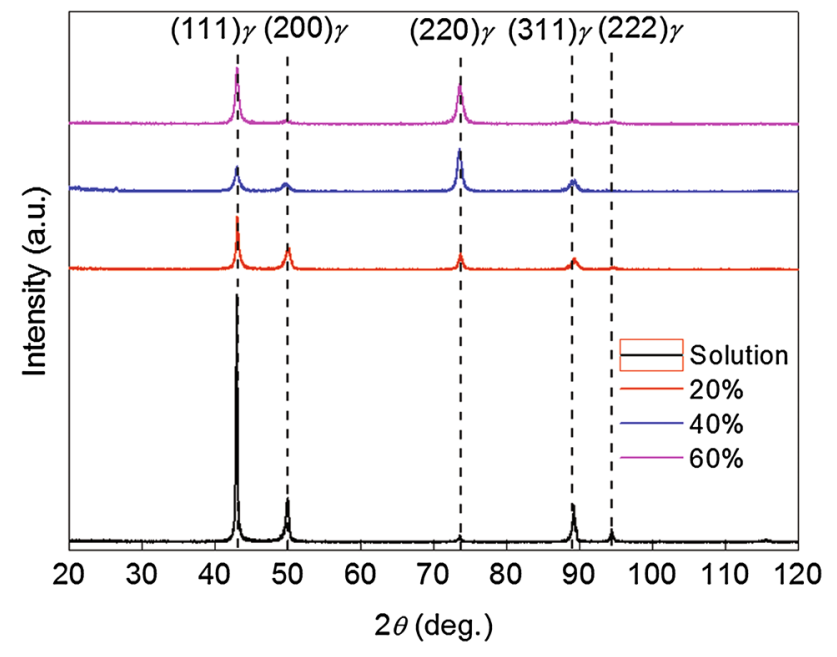

Fig. 2 XRD patterns of all kinds of cold-rolled NFHNSS specimens

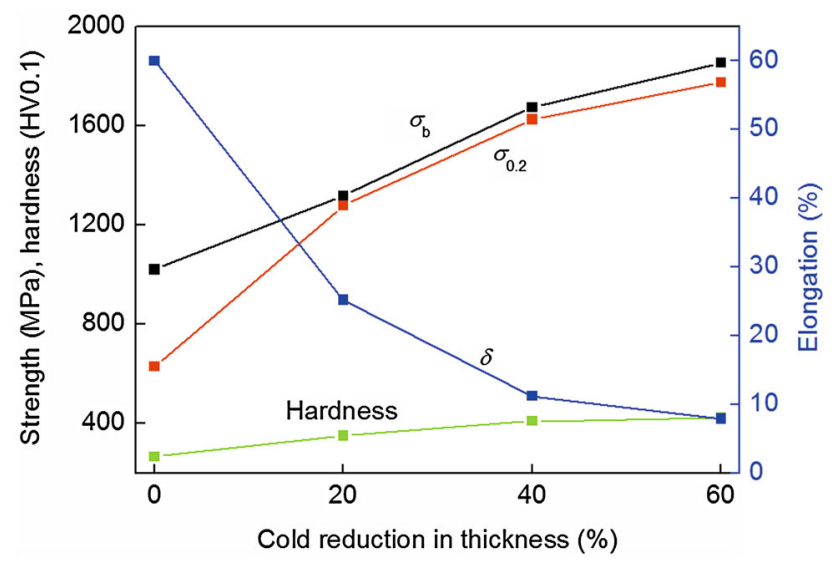

Fig. 3 Variations in mechanical properties of NFHNSS with respect to cold reduction in thickness

the elongation decreased gradually with the increase in cold reduction which should be attributed to the workhardening effect. Especially, the yield strength increased almost linearly when the cold deformation changed from 0 to $60 \%$. In addition, the difference between yield and tensile strength decreased with increasing cold reduction. According to the relationship of the stress and strain in the work-hardening region of engineering stress-strain curves of NFHNSS specimens, the work-hardening exponents for them were calculated to be $0.64,0.22,0.05$ and 0.04 , respectively, which showed a gradual decrease as the cold deformation increased.

\subsection{Corrosion Resistance}

The effect of cold deformation on the corrosion resistance of NFHNSS was investigated by means of electrochemical experiments, and cyclic polarization curves of all cold-

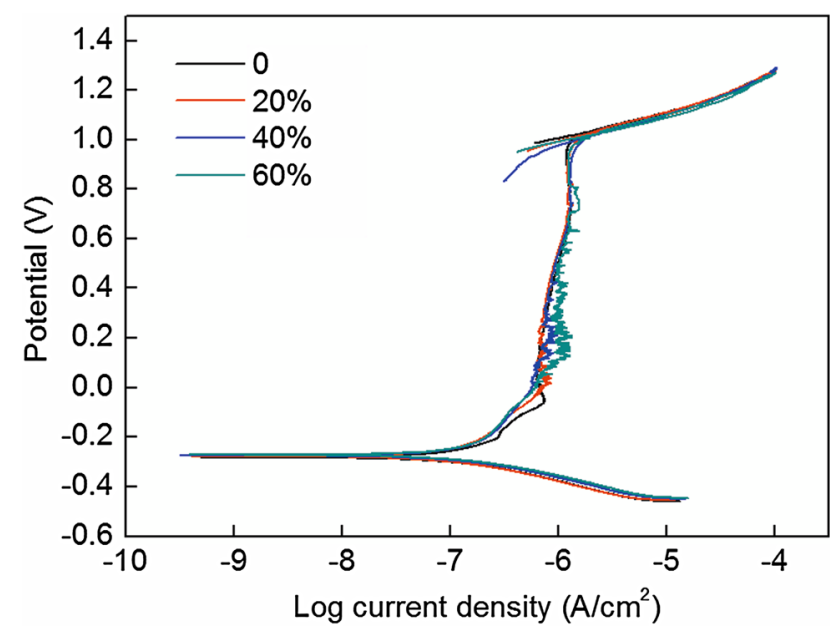

Fig. 4 Cyclic polarization curves and pitting potentials of cold-rolled NFHNSSs in Hank's solution

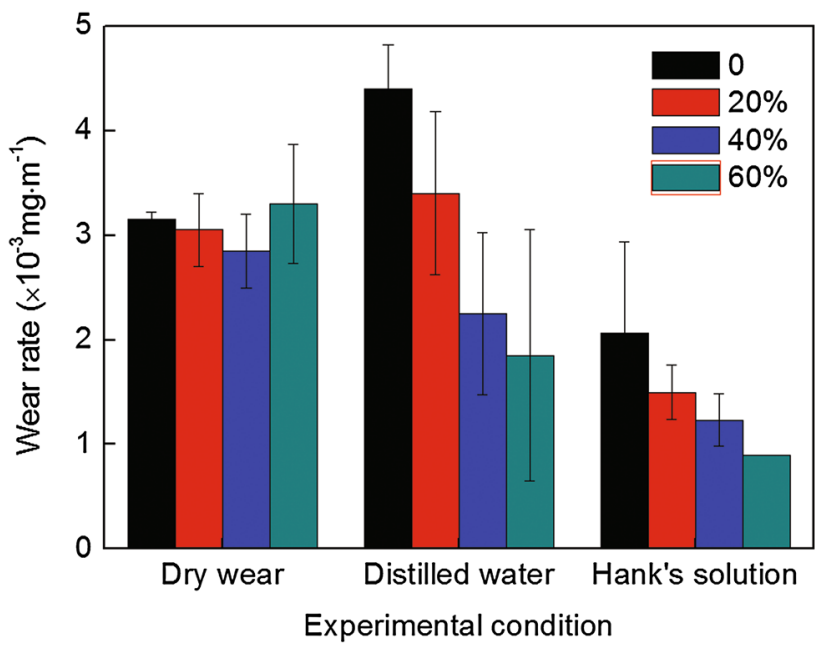

Fig. 5 Variations in wear rate as a function of cold reduction in thickness under different lubricating conditions

rolled NFHNSSs in the Hank's solution are shown in Fig. 4. Figure 4 shows that the potential changed with current density in the same way for each type cold-worked NFHNSS, resulting in a relatively good overlap of these curves, which meant similar electrochemical behaviors of them and no hysteresis loop could be found in each curve, indicating a strong capacity of repassivation of NFHNSS. When comparing the pitting corrosion potentials of all kinds of cold-rolled NFHNSSs, it can be discovered that all pitting corrosion potentials were very close and just decreased slightly with respect to cold deformation.

\subsection{Wear Properties}

Pin-on-disk sliding wear tests were performed without any lubricants in air, distilled water and Hank's solution, 

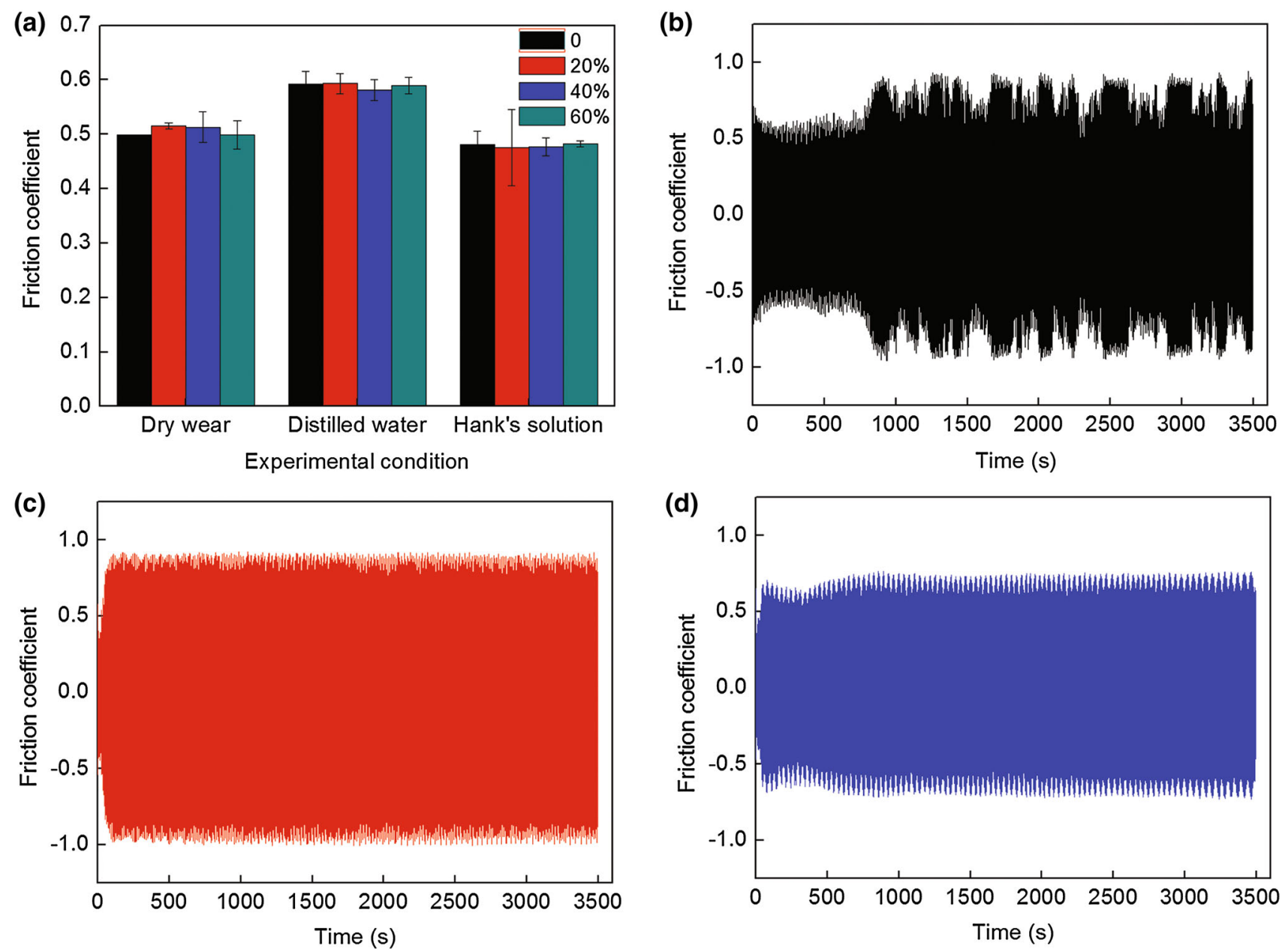

Fig. 6 a Variations in the friction coefficient as a function of cold reduction in thickness under various lubricating conditions; the typical friction coefficient-time curves obtained in dry wear tests $\mathbf{b}$; distilled water $\mathbf{c}$; Hank's solution $\mathbf{d}$

respectively. Figure 5 shows the variations in the wear rate (defined as weight loss per unit sliding distance) as a function of cold reduction in thickness under different lubricating conditions. As it is shown that in the dry wear tests, the wear rate decreased gradually with increasing cold deformation and then increased when the cold reduction in thickness reached $60 \%$. The $40 \%$ cold-rolled NFHNSS got the lowest wear rate and the wear rate of the $60 \%$ cold-rolled NFHNSS was even slightly larger than that of the annealed NFHNSS. It should be noted that the differences in wear rates in dry wear tests are not very large.

Cold deformation had a significant effect on the corrosion-wear property of NFHNSS in distilled water and Hank's solution, as shown in Fig. 5. In distilled water, as cold deformation increased, the wear rate of NFHNSS decreased monotonically. Compared with dry wear tests, the wear rates of both annealed and $20 \%$ cold-rolled NFHNSSs became larger while those of further cold-rolled specimens lowered to some extent in distilled water. In
Hank's solution, the effect of cold deformation on the wear rate of NFHNSS was similar to that in distilled water, but each kind of cold-rolled NFHNSS got small wear rate.

\subsection{Friction Coefficients}

It is well known that friction coefficient is a highly systematic parameter which is closely related to many factors such as contact material, temperature, normal load, sliding speed, lubricating condition and magnetic field. In this study, effects of contact materials (meaning NFHNSS with different cold reductions in thickness against same silicon nitride balls) and lubricating conditions on the friction coefficient were investigated. Figure 6 presents the variations in friction coefficient as a function of cold reduction in thickness together with the typical friction coefficienttime curves for NFHNSS recorded in dry wear tests, distilled water and Hank's solution, respectively. As shown in Fig. 6a, when sliding wear tests for all kinds of cold-rolled NFHNSSs were performed under the same lubricating 

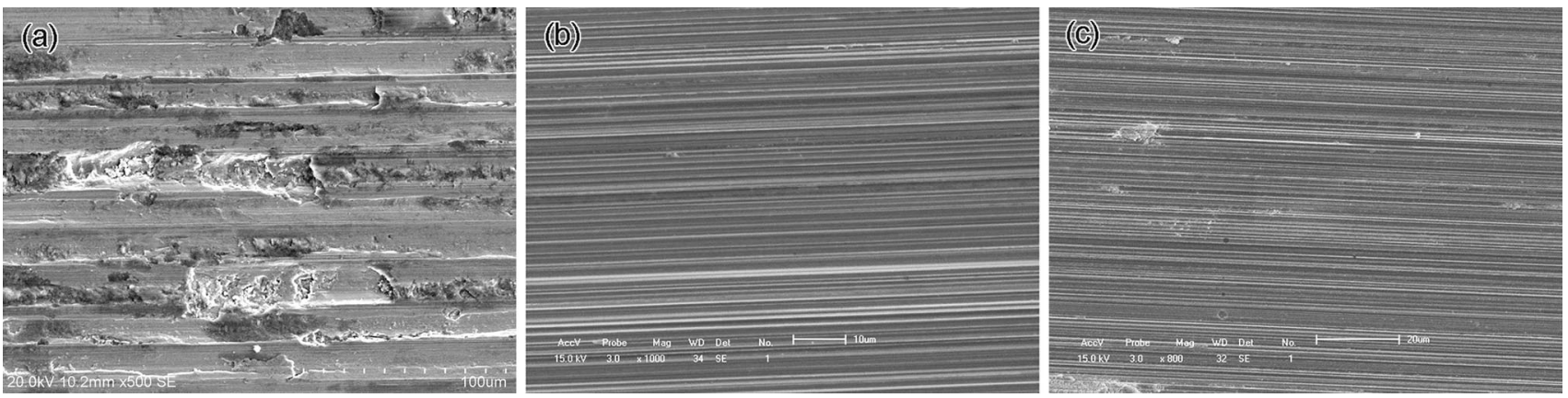

Fig. 7 SEM images of the typical worn surface for the annealed specimen in the dry wear tests a, the $40 \%$ cold-rolled specimen in distilled water b and the $40 \%$ cold-rolled specimen in Hank's solution c

condition, all friction coefficients were nearly equal, while changes in the lubricating condition had some influences on the friction coefficient. The friction coefficients obtained in distilled water were the largest than those obtained in both dry wear tests and Hank's solution. In addition, Fig. 6b-d shows that in dry sliding wear tests, the friction coefficient fluctuated obviously with increasing experimental time, but in the distilled water and Hank's solution, it is kept relatively stable during tests.

\subsection{Worn Surface and Its Micro-hardness}

The worn surfaces after sliding wear tests were observed using scanning electron microscopy (SEM). Since all kinds of cold-rolled specimens tested under the same lubricating condition displayed similar worn surface characteristics, a typical SEM image of worn surfaces for each lubricating condition is shown in Fig. 7, respectively. As shown in Fig. 7a, broad grooves caused by hard abrasive particles and/or silicon nitride friction counterpart by means of plowing along with micro-cutting, flaking pits due to brittle appalling and some gray black wear debris resulted from oxidation were all visible, which indicated a combination of different wear mechanisms consisting of abrasive wear, brittle flaking and oxidation wear. By contrast, worn surfaces of those specimens tested in both distilled water and Hank's solution were relatively smoother and exhibited a large amount of narrower micro-cutting slots; the only difference between them was that a few additional small round holes caused by corrosive attacks could be observed on the worn surfaces when sliding wear tests were carried out in Hank's solution (Fig. 7b, c). Thus, it can be confirmed that the dominant wear mechanism of NFHNSS in distilled water was abrasive wear while that in Hank's solution became abrasive wear associated with some corrosive pitting.

In general, surface properties such as hardness will change after sliding wear as a consequence of the effect of the contact stress combined with friction stress. To investigate the effect of the sliding wear on the hardness of worn surfaces of different cold-rolled NFHNSSs under various lubricating conditions, micro-hardness measurements were taken and the results are shown in Fig. 8. The worn surface hardness of all specimens increased to different degrees in comparison with their initial hardness. Interestingly, microhardness increments of those specimens tested in both distilled water and Hank's solution were not huge compared to those in dry wear tests and were very close; this is because solution lubricated friction pair and washed away wear debris from worn surface. In regard to specimens tested in dry sliding wear, their micro-hardness increments decreased with increasing cold deformation, which could be attributed to their decreasing capacities of work hardening [21].

\section{Discussion}

\subsection{Effect of Cold Deformation on the Microstructural and Mechanical Properties}

As tabulated in Table 1, the NFHNSS used in the present study contains high nitrogen content which is $0.90 \%$. Nitrogen is well known to be a strong austenite stabilizer which can inhibit forming of strain-induced martensite in spite of austenite undergoing large strain or cold deformation at low temperature [22]; hence, those specimens with increasing cold deformation presented only austenite without any other phases. In NFHNSS, many twins can also be observed from Fig. 1 which is mainly attributed to the effect of high nitrogen, since nitrogen can significantly reduce the stacking fault energy (SFE) of austenitic stainless steels, especially at low temperature [23] and low SFE makes the twins form easily during annealing or cold deformation.

Nitrogen can not only stabilizes the austenite, but also strengthens steels [24]. It has been established that interstitial nitrogen is the greatest solid-solution strengthening element which can cause a significant increase in yield 


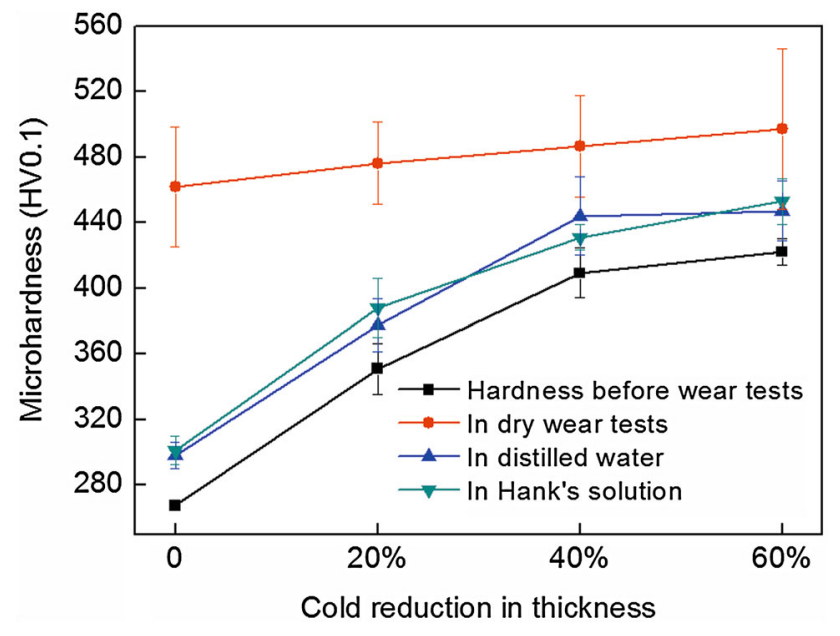

Fig. 8 Variations in micro-hardness of wear scars for NFHNSS with respect to cold reduction in thickness under different lubricating conditions

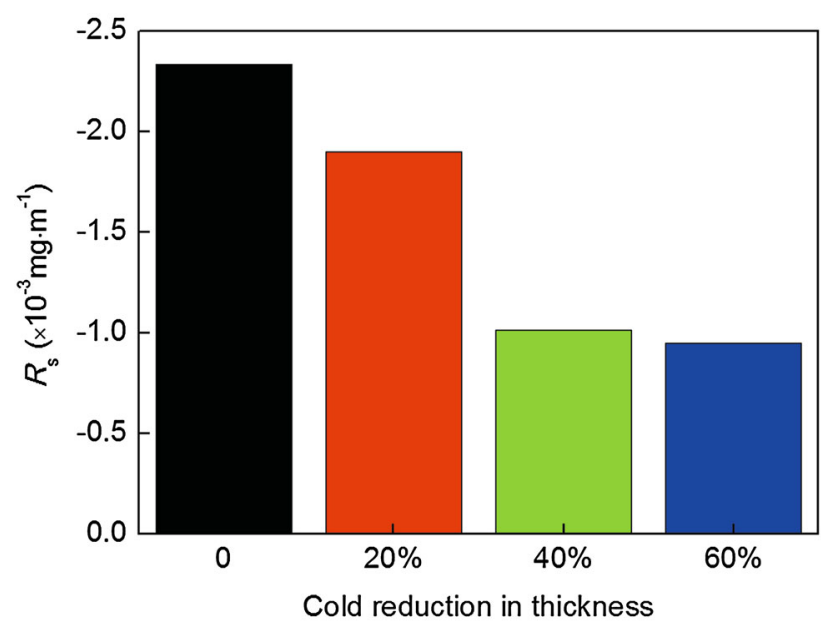

Fig. $9 R_{\mathrm{S}}$ of different cold-rolled NFHNSSs

strength without remarkably affecting ductility [25]; hence, it is understandable that the annealed NFHNSS possessed high yield strength accompanying with $60 \%$ elongation (see Fig. 3). In the present study, the yield strength of NFHNSS increased approximately linearly with cold reduction in thickness which can be explained in terms of three aspects, referring to solid-solution strengthening, grain boundary strengthening and strain hardening. NFHNSS exhibited high work-hardening capacity; the reason for this was the effect of nitrogen on the microstructures arising from cold work, which could be characterized by planar arrangement of slip dislocation and extensive twins (Fig. 1), since the higher the nitrogen content is, the shaper the planarity of dislocation slip and finer the structures will become $[26,27]$. On the other hand, the high manganese content of more than $15 \%$ in weight in
NFHNSS could also contribute to the formation of twins and the improved hardening behavior [28, 29].

\subsection{Effect of Cold Deformation on the Corrosion Resistance}

Nitrogen-alloyed austenitic stainless steels have been proved to possess excellent localized corrosion resistance which can be ascribed to the beneficial role of nitrogen. When a nitrogen-alloyed specimen is immersed in a corrosive solution containing chloride ions, the solid-solution nitrogen atoms can improve the pitting resistance by ways $[30,31]$ of (1) producing ammonium ions after dissolution to increase the local PH value, which can protect the pit sites from being further corroded; (2) segregating at the interface between alloy matrix and passive film to prevent attacks of chloride ions and then a stable passive film forms; (3) formation of nitrate ions which may act as prohibitor of pitting corrosion. In this study, nitrogen with the content of $0.90 \%$ interstitially dissolved in NFHNSS was helpful for the high pitting potentials, but as the cold reduction in thickness increased, pitting potentials decreased slightly (see Fig. 4). This can be understood as follows.

Firstly, the dislocation density in NFHNSS was increased during cold rolling, resulting in higher stored strain energy; as a consequence, the corrosion driving force was increased [32]. Investigations have indicated [33] that the electron work function (EWF) decreases with increasing cold deformation no matter what the deformation modes are, which means more active electrons caused by increased dislocation density and finally leads to increasing driving force for electrochemical reactions [34]. Secondly, micro-electrochemical heterogeneity such as nonuniform dislocation distribution and micro-texture, which were helpful for the formation of microelectrodes, was introduced in deformed NFHNSSs and they might also decrease resistance against corrosion [35]. Thirdly, short-range ordered (SRO) zones existing uniformly in NFHNSS could be destroyed by gliding dislocation during cold deformation at room temperature and thus brought about accelerated corrosion [36]. These three aspects discussed above all decreased the corrosion resistance of cold-rolled NFHNSSs.

However, on the one hand, the increased defect density introduced by cold deformation would help to enhance surface diffusion of nitrogen, which can be very effective in promoting the beneficial effects of nitrogen on pitting corrosion as mentioned above. On the other hand, there exist extensive deformation twins in large-strain NFHNSS specimens (Fig. 1); the twin boundary which belongs to low-angle grain boundary has lower energy compared to high-angle boundaries and can improve the corrosion 

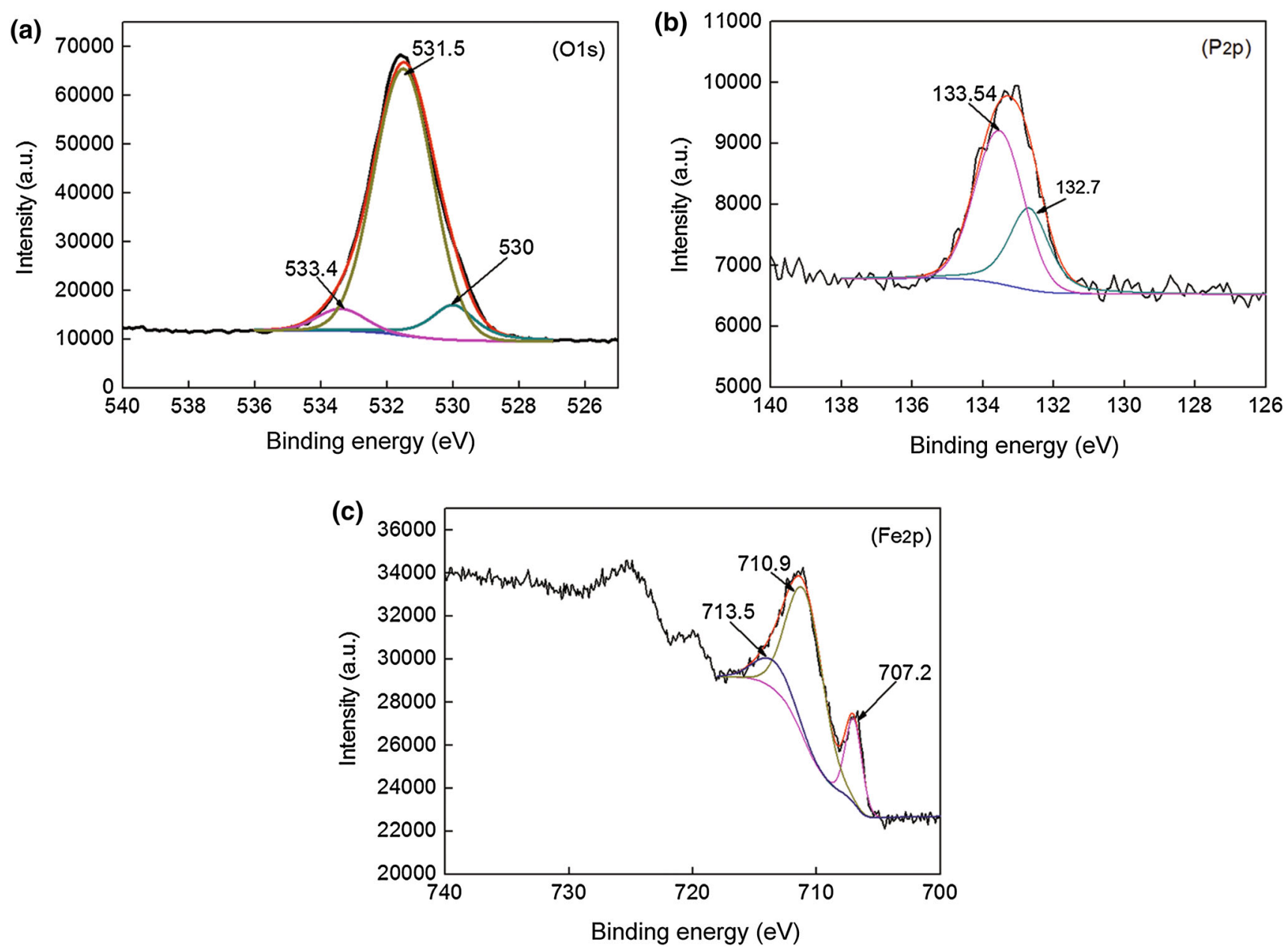

Fig. 10 X-ray photoelectron spectroscopy spectra of $\mathrm{O} 1 \mathrm{~s}, \mathrm{P} 2 \mathrm{p}$ and Fe2p of the worn surface of a 60\% cold-rolled NFHNSS tested in Hank's solution

resistance $[37,38]$. What is more, the NFHNSS possesses a strong capacity of repassivation, which can be confirmed by the cyclic polarization curves without hysteresis loops (see Fig. 4); therefore, although pitting can initiate on the specimen's surface, it is restricted from growing later. Thus, the latter three aspects play a significantly beneficial role in compensating for those detrimental effects of cold deformation on the corrosion resistance. In general, combined effects of all above factors resulted in the final corrosion experimental results.

\subsection{Effect of Cold Deformation on the Wear Resistance}

According to Fig. 5, NFHNSS exhibited different wear behaviors under various lubricating conditions. In dry wear tests, the results indicated that the increase in cold deformation did not lead to improvements of dry wear resistance accordingly. In the case of the annealed NFHNSS specimen, its low initial hardness and poor capacity of supporting the hardened layer on the worn surface caused by work-hardening effect resulted in relatively high wear rate. As cold reduction in thickness increased, the initial hardness increased, due to which the resistance of NFHNSS against wear was enhanced, whereas the further increasing cold deformation decreased the wear resistance, which can be mainly attributed to the prior severe plastic deformation. As for those NFHNSS specimens with $60 \%$ pre-deformation, they contained a large number of dislocation and substructures, their brittleness increased and plasticity decreased simultaneously; hence, when tested under dry wear condition, they could not accommodate the shear strain introduced by wear stress; as a consequence, voids and/or microcracks initiated at the place near to hardened layer surface and subsequently grew swiftly because of their little abilities to release the stress concentration at the tips of cracks [21, 39], finally accelerating the formation of brittle flaking (Fig. 7). Moreover, due to the outstanding work-hardening capacity of NFHNSS, the hardness of hardened surface layers on all kinds of cold-rolled specimens was not much 
different from each other (Fig. 8), based on which the small differences in dry wear rates of NFHNSS can be explained. In general, it may be concluded from the dry wear results that good wear resistance depends on not only the high hardness and strength, but also suitable plasticity, ductility and work-hardening capacity.

When sliding wear tests were carried out in distilled water, since the solution contained little corrosive ions such as $\mathrm{Cl}^{-}$, there was no corrosion affecting NFHNSS's wear resistance; thus, its wear behavior was mainly determined by the mechanical properties. As cold deformation increased, both initial hardness and strength of NFHNSS were improved markedly (Fig. 3) and its wear scar hardness increased as well; the ability of resisting wear of NFHNSS was enhanced gradually which resulted in reduction in wear rate. With regard to the annealed and 20\% cold-rolled NFHNSSs, because of their lower hardness of wear scars in distilled water compared to that in dry wear tests (Fig. 8), their wear rates became larger and wear resistance decreased. Nevertheless, in spite of lower wear scar hardness of 40 and $60 \%$ cold-rolled NFHNSSs than that obtained in dry wear tests, no brittle flaking occurred and few wear debris remained on the worn surface, both above two led to a decrease in wear rates.

In Hank's solution, as discussed above, NFHNSS's corrosion behavior nearly remained the same as cold deformation increased, while its wear resistance was improved gradually; this is easy to understand because of the increasing initial hardness, strength and wear scar hardness. However, as for all kinds of cold-rolled NFHNSSs, their wear rates were lower in Hank's solution than those obtained in distilled water, although there were an amount of corrosive ions in the Hank's solution. Many studies have reported [40-44] that when sliding wear tests are performed in a corrosive solution, the whole corrosionwear weight loss is not the simple sum of the weight loss caused only by corrosion and material loss removed by pure mechanical wear; the interaction between corrosion and wear, defined as synergistic effect, also plays an important role in corrosion-wear. In general, the corrosion can be accelerated by pure mechanical wear due to the removal of passive films, and the pure mechanical wear can be accelerated by corrosion as well by the way of promoting the initiation and propagation of cracks [45].

In the present corrosion-wear tests, the relationship between the total wear rate $\left(R_{\mathrm{t}}\right)$, pure corrosion rate $\left(R_{\mathrm{c}}\right)$, pure mechanical wear rate $\left(R_{\mathrm{m}}\right)$ and the wear rate caused by synergistic effect $\left(R_{\mathrm{S}}\right)$ can be expressed as following equation [45]:

$R_{\mathrm{t}}=R_{\mathrm{c}}+R_{\mathrm{m}}+R_{\mathrm{s}}$.

As discussed above, the NFHNSS possesses excellent corrosion resistance, in addition, each test lasts only $174 \mathrm{~min}$; hence, $R_{\mathrm{c}}$ is negligible. Equation (2) changes as
$R_{\mathrm{t}}=R_{\mathrm{m}}+R_{\mathrm{s}}$.

The wear rates obtained in distilled water can be regarded as $R_{\mathrm{m}}$, so $R_{\mathrm{s}}$ can be calculated using following equation:

$R_{\mathrm{s}}=R_{\mathrm{t}}-R_{\mathrm{m}}$.

According to Eq. (4) and Fig. 5, $R_{\mathrm{s}}$ are obtained and shown in Fig. 9. As shown, $R_{\mathrm{s}}$ are negative for different cold-rolled NFHNSS specimens and increase with increasing cold reduction. Therefore, negative $R_{\mathrm{S}}$ values indicated that there were other factors which played a beneficial role in decreasing the corrosion-wear rates.

The X-ray photoelectron spectroscopy of the worn surface of a $60 \%$ cold-rolled NFHNSS specimen tested in Hank's solution is shown in Fig. 10. According to previous literatures [46, 47], the binding energy of $\mathrm{O} 1 \mathrm{~s}$ at $533.4 \mathrm{eV}$ corresponds to the phosphate groups and adsorbed water and that of $\mathrm{Fe} 2 \mathrm{p}$ at $713.5 \mathrm{eV}$ determines the existence of iron phosphate, which is also confirmed by the binding energies of P2p at both 132.7 and $133.54 \mathrm{eV}$.

As listed in Table 2, the Hank's solution contained $\mathrm{HPO}_{4}{ }^{2-}$ and $\mathrm{H}_{2} \mathrm{PO}_{4}{ }^{-}$, which would be easily absorbed by the nascent surface created through mechanical wear, and subsequently, they reacted with NFHNSS to form metal phosphates such as $\mathrm{FePO}_{4}$ to act as boundary lubricating films, which could protect the worn surface from both corrosion and mechanical wear [48-50]. On the other hand, fine corrosion-wear debris might form and deposited on the worn surface to act as dry lubricants. Both of the above two processes would lead to a great decrease in wear rate, especially for the NFHNSS with low strain. Therefore, even though some pitting occurred during sliding tests (Fig. 7c), they contributed little to the whole wear rate. Based on the results of corrosion-wear tests, we can come to a conclusion that corrosion does not always accelerate the wear and other factors which are helpful for wear resistance should also be taken into account.

\subsection{Effect of Cold Deformation on Friction Coefficient}

Friction coefficient is usually connected to the surface condition of friction pairs. For those specimens tested under the same condition, similar worn surface characteristics led to nearly equal friction coefficient (Fig. 6). The difference is, in dry sliding wear tests, a mass of wear debris, a part of which had a certain fluidity, remained on the worn surface; as a result, friction coefficient fluctuated with test time due to the generation and movement of wear debris and was lower in contrast to that in distilled water. By comparison, when sliding wear tests were carried out in Hank's solution, the presence of the boundary films and 
fine wear particles acting as dry lubricant [4] remarkably decreased the friction coefficient. Of course, since there was no wear debris existing on the worn surface, the friction coefficient stayed relatively stable with increasing test time in both distilled water and Hank's solution.

\section{Conclusions}

1. The microstructure of NFHNSS was characterized by stable single-phase austenite together with many twins, and no strain-induced martensite could be found after cold rolling. The strength and hardness increased significantly while the elongation and work-hardening exponent decreased gradually as cold deformation increased.

2. With increasing cold deformation, NFHNSS's corrosion resistance is kept nearly same; wear rates in dry wear tests decreased gradually and then increased while they decreased monotonically in distilled water and Hank's solution; the lowest wear rate of NFHNSS was obtained in Hank's solution. The friction coefficient fluctuated with wear time significantly in dry wear tests but slightly in distilled water and Hank's solution; under the same condition, fiction coefficients were nearly equal.

3. The main wear mechanism in dry wear tests was a combination of abrasive wear, brittle flaking and oxidation wear. In distilled water, the dominant mechanism was only abrasive wear while it consisted of both abrasive wear and some pitting in Hank's solution.

Acknowledgments This work was financially supported by the National Natural Science Foundation of China (No. 31370976) and the National Basic Research Program of China (No. 2012CB619101).

\section{References}

[1] S.H. Teoh, Int. J. Fatigue 22, 825 (2000)

[2] S.F. E, L. Shi, Z.G. Guo, W.M. Liu, Bios. Bio. 1, 81 (2015)

[3] Q.Z. Chen, G.A. Thouas, Mater. Sci. Eng. R 87, 1 (2015)

[4] U.I. Thomann, P.J. Uggowitzer, Wear 239, 48 (2000)

[5] K. Yang, Y.B. Ren, Sci. Technol. Adv. Mater. 11, 1 (2010)

[6] M. Talha, C.K. Behera, O.P. Sinha, Mater. Sci. Eng. C 33, 3563 (2013)

[7] K. Yang, Y.B. Ren, P. Wan, Sci. China. Technol. Sci. 55, 329 (2012)

[8] H.B. Li, Z.H. Jiang, Z.M. Zhang, B.Y. Xu, F.B. Liu, J. Iron Steel Res. Int. 14, 330 (2007)

[9] M. Talha, C.K. Behera, O.P. Sinha, Mater. Sci. Eng., C 47, 196 (2015)
[10] N. Maruyama, M. Sanbe, Y. Katada, K. Kanazawa, Mater. Trans. 50, 2615 (2009)

[11] P. Wan, Y.B. Ren, B.C. Zhang, K. Yang, Mater. Sci. Eng. C 32, $510(2012)$

[12] H.B. Li, Z.H. Jiang, Y. Yang, Y. Cao, Z.R. Zhang, Int. J. Min. Met. Mater. 16, 517 (2009)

[13] M.H. Li, T.Y. Yin, Y.Z. Wang, F.F. Du, X.Z. Zou, H. Gregersen, G.X. Wang, Mater. Sci. Eng. C 43, 641 (2014)

[14] J.F.D. Santos, C.M. Garzón, A.P. Tschiptschin, Mater. Sci. Eng. A 382, 378 (2004)

[15] A. Basak, D.K. Roy, G.L. Dutta, Wear 184, 241 (1995)

[16] A.P. Tschiptschin, C.M. Garzón, D.M. Lopez, Tribol. Int. 39, 167 (2006)

[17] G.H. Zhou, H.Y. Ding, Y. Zhang, N.N. Li, Tribol. Int. 43, 891 (2010)

[18] D.J. Mills, R.D. Knutsen, Wear 215, 83 (1998)

[19] M.C. Young, J.Y. Huang, R.C. Kuo, Mater. Trans. 50(3), 657 (2009)

[20] S.T. Wang, K. Yang, Y.Y. Shan, L.F. Li, Acta Metall. Sin. 43(2), 171 (2007). (in Chinese)

[21] K.K. Ray, V. Toppo, S.B. Singh, Mater. Sci. Eng. A 420, 333 (2006)

[22] A. Basak, D.K. Roy, G.L. Dutta, Wear 184, 241 (1995)

[23] K.H. Lo, C.H. Shek, J.K.L. Lai, Mater. Sci. Eng. R 65, 39 (2009)

[24] H.Q. Chen, J.S. Liu, H.G. Guo, Acta Metall. Sin. (Engl. Lett.) 17(5), 767 (2004)

[25] J. Rawers, M. Grujicic, Mater. Sci. Eng. A 207, 188 (1996)

[26] P. Müllner, C. Solenthaler, P. Uggowitzer, M.O. Speidel, Mater. Sci. Eng. A 164, 164 (1993)

[27] T.H. Lee, C.S. Oh, S.J. Kim, S. Takaki, Acta Mater. 55, 3649 (2007)

[28] A. Sébastien, P.C. Jean, B. Olivier, Steel Res. Int. 73, 299 (2002)

[29] Y.N. Dastur, W.C. Leslie, Metall. Trans. A 12, 749 (1981)

[30] H. Baba, T. Kodama, Y. Katada, Corros. Sci. 44, 2393 (2002)

[31] R.C. Newman, T. Shahrabi, Corros. Sci. 27, 827 (1987)

[32] J.C. Scully, The Fundamentals of Corrosion, 3rd edn. (Pergamon Press, Oxford, 1990)

[33] D.Y. Li, Phys. Status Solidi A 191, 427 (2002)

[34] S.B. Yin, D.Y. Li, Mater. Sci. Eng. A 394, 266 (2005)

[35] E.M. Gutman, Mechanochemistry of Solid Surfaces (World Scientific Publishers, New Jersey, 1994)

[36] U.K. Mudali, P. Shankar, S. Ningshen, R.K. Dayal, H.S. Khatak, B. Raj, Corros. Sci. 44, 2183 (2002)

[37] A.Q. Lv, Y. Zhang, Y. Li, G. Liu, Q.H. Zang, C.M. Liu, Acta Metall. Sin. (Engl. Lett.) 19, 183 (2006)

[38] G.D. Chu, Y.H. Wei, D.Z. Li, Y. Tian, J. Iron. Steel. Res. Int. (Supplement 1-1) 18, 331 (2011)

[39] J.M. Wu, S.L. Zheng, Z.Z. Li, Y.W. Zeng, Wear 232, 25 (1999)

[40] T.C. Zhang, X.X. Jiang, S.Z. Li, Wear 199, 253 (1996)

[41] X.X. Jiang, S.Z. Li, C.T. Duan, M. Li, Wear 129, 293 (1989)

[42] M.H. Hong, S.I. Pyun, Wear 147, 69 (1991)

[43] A. Iwabuchi, J.W. Lee, M. Uchidate, Wear 263, 492 (2007)

[44] K.L. Dahm, Tribol. Int. 40, 1561 (2007)

[45] J. Jiang, M.M. Stack, A. Neville, Tribol. Int. 35, 669 (2002)

[46] R. Lu, K. Kobayash, H. Nanao, S. Mori, Tribol. Lett. 33, 1 (2009)

[47] J.C. Yan, X.Q. Zeng, T.H. Ren, E.V.D. Heide, Appl. Surf. Sci. 315, 415 (2014)

[48] T. Morimoto, Wear 169, 127 (1993)

[49] A.M.H.S. Lubis, M. Sudin, B. Ariwahjoedi, J. Appl. Sci. 12(24), $2503(2012)$

[50] D. Jiang, L.T. Hu, D.P. Feng, Lubr. Sci. 25, 195 (2013) 